\title{
Effect of Menstrual Cycle on Aerodynamic Measures among Singers and Nonsingers
}

\author{
Deepa N Devadiga ${ }^{1}$, Jyoti Pahwa², Jayashree S Bhat ${ }^{3}$
}

\begin{abstract}
Singer's vocal apparatus is comprised of her entire body and mind and is easily influenced by hormonal variations. The hormonal changes may have adverse effects on a singer's vocal performance. There is very little understanding about the aerodynamic measures among singers especially during the different phases of menstrual cycle in Indian population.

Aims and objectives: To study the effect of menstrual cycle on aerodynamic measures among singers and nonsingers. The objectives of the study were to profile aerodynamic measures in singers and nonsingers, to compare the aerodynamic measures between the singers and nonsingers, and to study the effect of menstrual phase on aerodynamic measures between singers and nonsingers.

Materials and methods: The participants in group I comprised of 30 nonsingers in the age range of $18-25$ years. Group II comprised of 15 trained singers (received training formally more than 3 years), and group III had 15 untrained singers in the age range of 18-25 years. The forced vital capacity (FVC), forced expiratory volume in first second (FEVI), and peak expiratory airflow (PEF) were recorded. Descriptive statistics and repeated measure of ANOVA were done to study the effect of menstrual cycle on aerodynamic measures among singers and nonsingers using SPSS 16.0.

Results: In the present study, the overall mean scores obtained for all the aerodynamic measures were reduced during menstrual phase as compared to the aerodynamic measures obtained during the follicular phase among both singers and nonsingers.

Keywords: Aerodynamics, Follicular phase, Menstrual cycle, Nonsingers, Singers.

Otorhinolaryngology Clinics: An International Journal (2019): 10.5005/jp-journals-10003-1323
\end{abstract}

\section{INTRODUCTION}

The menstrual cycle is a naturally occurring event resulting from hormonal changes in the female body. These variations occur prior and after the menstrual cycle. ${ }^{1}$ It is reported that females experience continuous fluctuations in their hormones during the cycle. ${ }^{2}$ Most women of child-bearing age experience menstruation approximately every 28 days, in four phases: the menstrual, the follicular, an ovulation, and the luteal phases. The hormonal effects of the body tend to change with the phases of menstrual cycle. During the initiation of the menstrual cycle, the menstrual phase has low estrogen and progesterone. In the follicular phase, the progesterone is low but the level of estrogen increases. During the luteal phase, contrary to menstrual phase, both the estrogen and progesterone is high. The premenstrual phase is similar to menstrual phase with low level of estrogen and progesterone.

An efficient vocal system with a balance of airflow and laryngeal muscle activity ${ }^{3}$ is essential especially in singers as they require exquisite control and coordination between breathing and pulmonary system in order to produce good esthetic voice. Evidence has suggested that premenstrual symptoms that affect the body may have adverse effects on a singer's vocal performance. ${ }^{4}$ The beginning of the menstrual cycle, the follicular phase, is marked by increased amounts of estrogen and markedly lower levels of progesterone.

The vessels in the nasal passages dilate, resulting in changes in patency and the singer's perception of her voice. In the second half of the menstrual cycle, the luteal phase, progesterone levels increase to a greater degree than estrogen. Progesterone promotes sloughing of the laryngeal epithelium and works against proliferation. It also makes the glandular secretions more viscous, leading to a decrease in vibratory efficiency and possibly increased
${ }^{1}$ Department of Speech and Hearing, Manipal College of Health Professions, Manipal Academy of Higher Education, Manipal, Karnataka, India

${ }^{2,3}$ Department of Audiology and Speech Language Pathology, Kasturba Medical College (A Unit of MAHE, Manipal), Mangaluru, Karnataka, India

Corresponding Author: Deepa N Devadiga, Department of Speech and Hearing, Manipal College of Health Professions, Manipal Academy of Higher Education, Manipal, Karnataka, India, Phone: +91 9986447191, e-mail: deepa.n@manipal.edu

How to cite this article: Devadiga DN, Pahwa J, Bhat JS. Effect of Menstrual Cycle on Aerodynamic Measures among Singers and Nonsingers. Int J Otorhinolaryngol Clin 2019;11(2):38-40.

Source of support: Nil

Conflict of interest: None

cell damage. These changes are responsible for changes in the voice during the menstrual cycle.

Previous studies have suggested that respiratory function is influenced by female sexual hormones, especially progesterone, which could increase ventilatory response during the luteal phase at rest ${ }^{5}$ and at exercise. ${ }^{6}$ Others studies have shown that progesterone and estradiol act together to produce increased ventilation in rats., ${ }^{7,8}$ However, in humans, the results are contradictory. For instance, it has been demonstrated that the response to hypoxia and hypercapnia is higher in the luteal when compared to the follicular phase of the menstrual cycle, 6,9 but the chemosensitivity was not associated with hormonal fluctuation. ${ }^{10,11}$ These changes are responsible for changes in the vocal apparatus during the menstrual cycle, thereby causing an adverse effect on singers performance. This is why professional

(c) The Author(s). 2019Open Access This article is distributed under the terms of the Creative Commons Attribution 4.0 International License (https://creativecommons. org/licenses/by-nc/4.0/), which permits unrestricted use, distribution, and non-commercial reproduction in any medium, provided you give appropriate credit to the original author(s) and the source, provide a link to the Creative Commons license, and indicate if changes were made. The Creative Commons Public Domain Dedication waiver (http://creativecommons.org/publicdomain/zero/1.0/) applies to the data made available in this article, unless otherwise stated. 
singers should be informed about the condition of the laryngeal muscular tension and other changes that occur during the menstrual cycle.

\section{Need of the Study}

Singers require fine control of the respiratory, phonatory, and resonatory systems in order to produce good esthetic voice. Singing practice comprises of a strong and fast inspiration, which is followed by extended and regulated expiration. An accurate control of breath plays a major role during singing. It is imperative for the speech pathologist to be aware of the special need of the singers voice as their livelihood demands efficient and enduring vocal function and excellent vocal technique that produces expected vocal fitness required to sing. There is very little understanding about the aerodynamic measures among singers especially during the different phases of menstrual cycle in Indian population. Hence, the present study is an attempt in this direction.

\section{Aims and Objectives}

\section{Aims}

To study the effect of menstrual cycle on aerodynamic measures among singers and nonsingers.

\section{Objectives}

- To profile aerodynamic measures in singers and nonsingers.

- To compare the aerodynamic measures between the singers and nonsingers.

- To study the effect of menstrual phase on aerodynamic measures between singers and nonsingers.

\section{Materials and Methods}

\section{Participants}

The participants in group I comprised of 30 nonsingers in the age range of 18-25 years. Group II comprised of 15 trained singers (received training formally more than 3 years) and group III had 15 untrained singers in the age range of $18-25$ years. All the participants had 28 days of menstrual cycle and were normal healthy individuals with no vocal complaint, past history of any vocal, respiratory, and neurological problems. Individuals who were on oral contraceptives, or impaired respiratory, cardiac function, individuals with auditory impairment, or any other associated congenital laryngeal anomalies, laryngeal malignancy, and history of laryngeal/thyroid surgery, neurological, and neuromuscular diseases were excluded from the study.

\section{Procedure}

Informed consent was obtained from all the participants. The evaluation was carried out using handheld Electronic Spirometer (SP 10). The mouthpiece was kept on participant's mouth and the participant was instructed to take a deep inhalation followed by a forceful exhalation through mouth. The forced vital capacity (FVC), forced expiratory volume in first second (FEVI), and peak expiratory airflow (PEF) were recorded in standing position twice during the two phases of the menstrual cycle. The recordings were done on day 2 (menstrual phase) and day 12 (follicular phase), following the start date of menses. Descriptive statistics and repeated measure of ANOVA were done to study the effect of menstrual cycle on aerodynamic measures among singers and nonsingers using SPSS 16.0.

\section{Results}

In the present study, the overall mean scores obtained for all the aerodynamic measures FVC $(2.19 \pm 0.3)$, FEV1 $(2.10 \pm 0.25)$, and PEF $(5.00 \pm 1.11)$ were reduced during menstrual phase as compared to the aerodynamic measures FVC $(2.48 \pm 0.28)$, FEV1 $(2.28 \pm 0.27)$, and PEF $(5.17 \pm 1.00)$ obtained during the follicular phase among both singers and nonsingers. It was observed that the aerodynamic measures FVC $(2.19 \pm 0.3)$, FEV1 $(2.10 \pm 0.25)$, and PEF $(5.00 \pm 1.11)$ obtained during the menstrual phase among the nonsingers were higher compared to the trained singers FVC $(2.17 \pm 0.3)$ and PEF (4.93 $\pm 1.12)$ except for FEV1 $(2.15 \pm 0.33)$. Among the untrained singers, it was observed that the mean obtained for all the aerodynamic measures FVC (2.04 \pm 0.23$)$, FEV1 (1.91 \pm 0.21$)$, and PEF (4.51 \pm 1.01) was reduced as compared to both the nonsingers and trained singers. In the case of follicular phase, overall mean obtained for aerodynamic measures for nonsingers FVC $(2.48 \pm 0.28)$, FEV1 (2.28 $\pm 0.27)$, and PEF $(5.17 \pm 1.00)$ was reduced as compared to trained singers FVC ( $2.48 \pm 0.33)$, FEV1 $(2.35 \pm 0.35)$, and PEF $(5.19 \pm 1.01)$ It was observed that the mean obtained for all the aerodynamic measures among untrained singers FVC $(2.42 \pm 0.38)$ and FEV1 $(2.18$ $\pm 0.23)$ except for PEF (5.54 \pm 0.73$)$ was reduced as compared to nonsingers and trained singers. The repeated measure of ANOVA revealed significant effect of cycle on all the aerodynamic measures, FVC, $F(1,57)=59.37, p<0.05$, FEV1, $F(1,57)=28.45, p<0.05$, and PEF, $F(1,57)=0.37, p<0.05$. However, there was no significant difference seen between the groups.

\section{Discussion}

The results of the study indicate the effect of menstrual phase on aerodynamic measures in all the groups. It was observed that the aerodynamic measures were higher in follicular phase as compared to menstrual phase. Estrogen can have an effect on pulmonary functions among the females. ${ }^{12,13}$ Evidence suggests that in females who are having regular cycle, the estrogen levels increase during the follicular phase, ${ }^{14}$ which is consensus with the present study. The estrogen replacement therapy has also shown a significant improvement on lung respiratory function. ${ }^{15}$ Increase in FEV1 was observed to be higher among such females, which is in line with the present study. It could be probably due to the presence of abdominal cramps during the menstrual cycle, which can restrict and prevent them from maximum forceful expiration. Among the measures considered for the present study, PEF was observed to be more relevant measure among all the aerodynamic measures for assessment during the menstrual cycle. This could be due to the fact that this parameter is effort dependent, and the forced expiration is not required to be extended to residual volume. ${ }^{16}$ However, it was statistically not significant, which could be due to small sample size.

\section{Summary and Conclusion}

It is clear that the aerodynamic measures are susceptible to hormonal changes. The present study suggests that it is important for us to account the menstrual phase during the aerodynamic evaluation as it can have an impact on the diagnosis and further management. Singers should be aware with these hormonal issues as these changes may have an adverse effect on their performance. 


\section{Compliance with Ethical Standards Ethical Approval}

All procedures performed in studies involving human participants were in accordance with the ethical standards of the Institutional and/or National Research Committee. Informant consent was obtained from all the participants.

\section{References}

1. Emerich K. Pregnancy and the Voice. Gould Voice Center; 2000.

2. Da Silva SB, Viana ED, de Sousa MB. Changes in peak expiratory flow and respiratory strength during the menstrual cycle. Respir Physiol Neurobiol 2006;150(2-3):211-219. DOI: 10.1016/j.resp.2005. 03.001.

3. Price K. The effects of vocal function exercises on the lung function of trained female singers: a pilot investigation, Doctoral dissertation. Victoria University; 2017.

4. Davis CB, Davis ML. The effects of premenstrual syndrome (PMS) on the female singer. J Voice 1993;7(4):337-353. DOI: 10.1016/S08921997(05)80257-7.

5. White DP, Douglas NJ, Pickett CK, et al. Sexual influence on the control of breathing. J Appl Physiol Respir Environ Exerc Physiol 1983;54(4):874-879. DOI: 10.1152/jappl.1983.54.4.874.

6. Williams TJ, Krahenbuhl GS. Menstrual cycle phase and running economy. Med Sci Sports Exerc 1997;29(12):1609-1618. DOI: 10.1097/00005768-199712000-00010.

7. Hannhart BE, Pickett CK, Moore LG. Effects of estrogen and progesterone on carotid body neural output responsiveness to hypoxia. J Appl Physiol (1985) 1990;68(5):1909-1916. DOI: 10.1152/ jappl.1990.68.5.1909.

8. Bayliss DA, Millhorn DE. Central neural mechanisms of progesterone action: application to the respiratory system. J Appl Physiol (1985) 1992;73(2):393-404. DOI: 10.1152/jappl.1992.73.2.393.

9. Schoene RB, Robertson HT, Pierson DJ, et al. Respiratory drives and exercise in menstrual cycles of athletic and nonathletic women. J Appl Physiol Respir Environ Exerc Physiol 1981;50(6):1300-1305. DOI: 10.1152/jappl.1981.50.6.1300.

10. Loeppky JA, Scotto P, Charlton GC, et al. Ventilation is greater in women than men, but the increase during acute altitude hypoxia is the same. Respir Physiol 2001;125(3):225-237. DOI: 10.1016/S00345687(00)00221-8.

11. Muza SR, Rock PB, Fulco CS, et al. Women at altitude: ventilatory acclimatization at 4,300 m. J Appl Physiol (1985) 2001;91(4):1791-1799. DOI: 10.1152/jappl.2001.91.4.1791.

12. Cevrioglu AS, Fidan F, Unlu M, et al. The effects of hormone therapy on pulmonary function tests in postmenopausal women. Maturitas 2004;49(3):221-227. DOI: 10.1016/j.maturitas.2004.01.009.

13. Pata O, Atiş S, Öz AU, et al. The effects of hormone replacement therapy type on pulmonary functions in postmenopausal women. Maturitas 2003;46(3):213-218. DOI: 10.1016/S0378-5122(03)00191-9.

14. Knobil E. The menstrual cycle and its neuroendocrine control. Physiol Reprod 1988. 1971-1994.

15. Stipic I, Polasek O, Vulic M, et al. Estrogen replacement therapy improves pulmonary function in postmenopausal women with genital prolapse. Rejuvenation Res 2012;15(6):596-600. DOI: 10.1089/ rej.2012.1337.

16. Devadiga $D$, Varghese $A L$, Bhat J, et al. Peak flow measure: an index of respiratory function? Int J Health Sci Res 2015;5(2):240-245. 